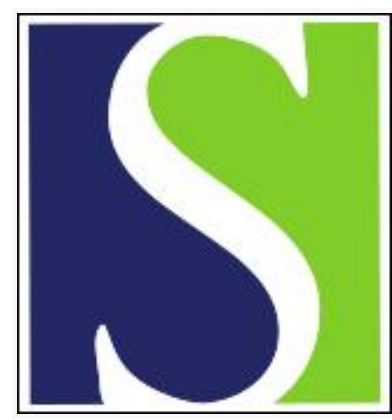

Scand J Work Environ Health 1991;17(2):123-132

https://doi.org/10.5271/sjweh.1725

Issue date: Apr 1991

Assessment of genotoxic exposure in Swedish coke-oven work by different methods of biological monitoring.

by Reuterwall C, Aringer L, Elinder CG, Rannug A, Levin JO, Juringe L, Onfelt A

Affiliation: National Institute of Occupational Health, Solna, Sweden.

This article in PubMed: www.ncbi.nlm.nih.gov/pubmed/2047814

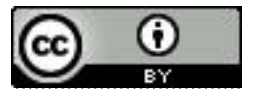




\title{
Assessment of genotoxic exposure in Swedish coke-oven work by different methods of biological monitoring
}

\author{
by Christina Reuterwall, PhD, ${ }^{1}$ Leif Aringer, MD, ${ }^{2}$ Carl-Gustaf Elinder, MD,, 3 \\ Agneta Rannug, $\mathrm{PhD},{ }^{1}$ Jan-Olof Levin, $\mathrm{PhD},{ }^{4}$ Leif Juringe, ${ }^{1}$ Agneta Önfelt, $\mathrm{PhD}{ }^{1}$
}

\begin{abstract}
REUTERWALL C, ARINGER L, ELINDER C-G, RANNUG A, LEVIN J-O, JURINGE L, ÖNFELT A. Assessment of genotoxic exposure in Swedish coke-oven work by different methods of biological monitoring. Scand $J$ Work Environ Health 1991;17:123-32. This study evaluated the results of several biological methods used simultaneously to monitor coke-oven work. Blood samples from 44 male coke-oven workers and 48 male referents, matched for age and smoking/snuff consumption, were examined for cytogenetic damage in lymphocytes. Urinary thioether excretion was determined for 62 , and urine mutagenicity for 31 , of the subjects, who followed a standardized diet during the urine sampling. Exposure to polycyclic aromatic hydrocarbons varied with work task, the ambient air levels of benzo[a]pyrene sometimes exceeding $5 \mu \mathrm{g} / \mathrm{m}^{3}$. Cytogenetic damage, urine mutagenicity, and thioether excretion did not differ between the groups. The smokers, however, had significantly higher sister chromatid exchange frequencies, urine mutagenicity, and thioether excretion than the nonsmokers. The absence of biological indications of genotoxic exposure was unexpected and indicates that the studied methods are not adequate to assess the carcinogenic risks of Swedish coke-oven workers.
\end{abstract}

Key terms: chromosome aberrations, micronuclei, occupational exposure, peripheral lymphocytes, polycyclic aromatic hydrocarbons, sister chromatid exchange, urinary thioethers, urine mutagenicity, work environment.

Analyses of urine mutagenicity, urinary thioether excretion, and cytogenetic damage in peripheral lymphocytes are recognized methods for monitoring human occupational exposure to mutagenic/carcinogenic agents (1). However, there is a need for more systematic studies of the potential benefits and limitations of the different methods. This study attempts to elucidate the benefits and limitations of these tests by applying the tests to an occupational group with presumed genotoxic exposure, namely, coke-oven workers in the Swedish steel industry.

Coke-oven work was chosen for several reasons. The International Agency for Research on Cancer (IARC) has classified coke production as being carcinogenic to humans and benzo[a]pyrene as probably carcinogenic to humans (2). Coke-oven workers have been monitored previously by analyses of cytogenetic damage (3-5), urine mutagenicity $(4,6-8)$, and urinary thioether excretion (9), and the results have sometimes indicated effects and sometimes not. The results of earlier occupational hygiene analyses from the coke works in our study have indicated exposure to polycyclic aromatic hydrocarbons, including benzo[a]py-

1 National Institute of Occupational Health, Solna, Sweden.

2 National Board of Occupational Safety and Health, Solna, Sweden.

3 Department of Medicine, Karolinska Hospital, Stockholm, Sweden.

${ }^{4}$ National Institute of Occupational Health, Umeá, Sweden.

Reprint requests to: Dr C Reuterwall, Department of Occupational Medicine, National Institute of Occupational Health, S-171 84 Solna, Sweden. rene. The coke-oven workers were thus considered to have an increased cancer risk, and we expected to find at least some significant effects in the biological monitoring systems applied.

\section{Subjects and methods}

\section{Study group and sampling scheme}

The study was carried out at a Swedish steel works. Blood and urine samples were collected for analyses of urinary excretion of thioethers, urine mutagenicity, and cytogenetic damage (chromosome aberrations, micronuclei, sister chromatid exchange). Air samples were collected for occupational hygiene analyses. The exposed subjects were chosen from the approximately 120 coke-oven workers employed at the steel works, and the referents were chosen from the nearly 500 steel roll mill workers at the same plant. According to previous occupational hygiene measurements, the steel roll mill workers were not exposed to detectable amounts of polycyclic aromatic hydrocarbons, carbon monoxide, sulfur dioxide, or organic solvents. Coke production and steel rolling were both shift work, with the same shift cycle of four afternoons, four mornings, four nights, and $7 \mathrm{~d}$ off duty. There were five shift teams at each workplace. In coke production, one additional team worked days only.

The following requirements determined the study design: (i) for maximal exposure the exposed subjects should have worked primarily in the highest exposed 
jobs (ie, on top of or in the immediate vicinity of the coke ovens); the urine samples were to be collected immediately after a completed workshift, to reflect the acute exposure, and late in the shift cycle (during a night shift), to include also possible effects of accumulated exposure; (ii) for representativity and comparability, all shift teams were to be included in the study; furthermore, samples from both the exposed workers and the referents were to be collected at each sampling occasion and analyzed together; (iii) the subjects had to be healthy (no chronic or acute disease, no current medication) and belong to one of the following three categories with respect to smoking and snuff habits: smoker ( $\geq 10$ cigarettes/day but no snuff use), snuff user (snuff user but nonsmoker), no tobacco user; (iv) for an improved sensitivity of the urine analyses, the subjects were to follow a standardized diet prior to and during the urine sampling period.

The subjects were stratified by smoking habits because of the well-documented effects of cigarette smoking on all the biological parameters (10). The study design was also intended to eliminate or control for other factors shown or suspected to be modifiers for one or several of the studied outcomes. Such factors included certain diseases and medications (11-14), excessive alcohol consumption (15), and gender and age, which may modify levels of cytogenetic damage (16-19). Dietary factors have been shown to influence the results of thioether analyses (20) and also urine mutagenicity tests $(21-22)$, and the diet restrictions were introduced to reduce the influence of such factors (20).

The final study group comprised 92 men (44 exposed coke-oven workers and 48 steel roll mill referents, matched on smoking quantity ( \pm 5 cigarettes/ $\mathrm{d}$ for the smokers), snuff habits, and age ( \pm 5 years). The median age was 42.5 years in the exposed group and 39 years in the reference group, and median employment time was 13 and 9 years, respectively. The smokers in the exposed group smoked 10-25 (median 15) cigarettes $/ \mathrm{d}$; the corresponding figure for the referents was $15-30$ (median 20) cigarettes/d. The snuff users consumed 50-350 (median 125) g/week in the exposed group and 50-300 (median 150) g/week in the reference group.

The exposed group represented 12 different jobs, and each subject had held his current job for at least one year. None of the referents had been occupationally exposed to potential genotoxic agents during the last three years, and no subject (exposed or referent) was using genotoxic agents in connection with leisure-time activities; this information was ascertained through the use of a questionnaire. Ex-smokers who had stopped smoking more than three years ago were classified as nonsmokers; other ex-smokers were not included in the study. In this presentation, nonsmokers refers to the combined group of snuff users and subjects not using tobacco at all.

Air, blood, and urine samples were collected on six occasions during six weeks (February-March): once during the last (fourth) night shift in the shift cycle, four times during the second night shift, and once during the day (coke-oven workers only).

\section{Ambient air sampling and analysis}

The occupational hygiene analyses focused on polycyclic aromatic hydrocarbons (PAH), and benzene, but the carbon monoxide and sulfur dioxide levels were also determined.

Polycyclic aromatic hydrocarbons and benzene. Selected subjects - only nonsmokers - carried personal air sampling equipment throughout an 8-h workshift. The sampling scheme was designed to include measurements from all the jobs included in the study. These jobs are listed in figure 1. Particle phase $\mathrm{PAH}$ was collected on glass-fiber filters, and the gas phase PAH on adsorbent tubes containing Amberlite XAD-2 (23). PAH quantities were determined by reversed-phase high-performance liquid chromatography and a reference solution, containing $14 \mathrm{PAH}$ (anthracene, benz[a]anthracene, dibenz[a,h]anthracene, benzo[a]fluorene, benzo[a]pyrene, benzo[b]fluoranthene, benzo[k]fluoranthene, benzo[g,h,i]perylene, chrysene, fluoranthene, fluorene, naphthalene, phenanthrene, pyrene) was used for the identification and quantitation of the single PAH (23). Benzene was collected on active charcoal, extracted by carbon disulfide, and quantified by gas chromatography.

Carbon monoxide and sulfur dioxide. The sampling sites represented almost all work areas within the coke works, while only areas with a potential for carbon monoxide and/or sulfur dioxide occurrence were sampled in the steel roll mill. The air concentrations of carbon monoxide and sulfur dioxide were estimated from color changes in Dräger test tubes.

\section{Urine sampling and diet restrictions}

Urine samples were collected for the mutagenicity analysis at the end of the workshift and, for the exposed subjects, also after $7 \mathrm{~d}$ off work. Urine samples were collected for the thioether analysis at the same times and also immediately before the beginning of the workshift. The samples were transferred to a deep freezer within $1 \mathrm{~h}$ of the sampling and stored at $-20^{\circ} \mathrm{C}$ until the analyses were performed.

The creatinine concentration was determined in each sample as described by Bartels et al (24); this concentration was used to correct measures of thioether excretion and urine mutagenicity for inter- and intraindividual differences in urine concentration in the original samples.

All of the subjects were instructed to keep a special diet for the $16 \mathrm{~h}$ preceding the preshift sampling occasion and also during the shift when samples were collected. The subjects who left an off-work urine sam- 
ple were requested to follow the diet for $16 \mathrm{~h}$ before that sampling also. We provided all food during these 24 -h periods. The diet was based on chicken, potatoes, bread, and dairy products, while vegetables of the Cruciferae family (eg, horseradish, cabbage, onion, garlic, turnip) were excluded. This diet was developed by our laboratory and has previously been shown to reduce considerably the background levels in thioether excretion analyses (20).

\section{Determination of urinary thioether excretion}

Altogether, samples from 62 persons in the study group were analyzed for thioether excretion. The reduced number was due to absence during the workshift when the sampling took place (13 persons), temporary change of jobs (four persons), diet not strictly kept (two persons). Furthermore, urine samples were not collected from those smokers who smoked $<15$ cigarettes/d (11 persons). This practice gave a slightly higher median cigarette consumption among the exposed subjects selected for the urine sampling, namely, 18 cigarettes/d as compared with 15 cigarettes/d for all the exposed subjects. Thioether excretion was determined in pre- and postshift samples from 28 exposed subjects and 34 referents and in off-work samples from 23 exposed subjects. The thioethers were extracted from the urine samples with ethyl acetate and hydrolyzed with sodium hydroxide. The thiols were then determined spectrophotometrically with the reagent of Ellman's. The analyses were performed exactly as described by Aringer \& Lidums (20). The results of the analyses were related to the creatinine concentration.

\section{Determination of urine mutagenicity}

Samples from 36 subjects, randomly chosen from the 62 subjects examined for thioether excretion, were selected for the mutagenicity analysis. Samples from five subjects were lost during the preanalysis treatment, samples from 31 subjects thus being analyzed. The sample treatment and mutagenicity testing were carried out according to the standardized procedure described by Maron \& Ames (25) and modified by Rannug et al (26). For each subject four volumes of urine concentrate, corresponding to $0.5,1,2$, and 4 $\mathrm{ml}$ of urine, were tested on Salmonella typhimurium TA98 with S9 mix added. The mutagenic activity (number of mutant colonies per milliliter of urine) was estimated from the linear part of the subject's sampleresponse curve, drawn from the test results of the four volumes (26). The mutagenic activity was also expressed as the number of mutants per micromole of creatinine.

The level of spontaneous back mutation in the TA98 strain was determined from tests on control plates with dimethyl sulfoxide added ( $60-160 \mu \mathrm{l} /$ plate). Control plates with $0.2 \mu \mathrm{g}$ of 2 -aminoanthracene were used to test the sensitivity to mutagenic agents in the TA98 strain and to test the metabolic capacity of the liver enzyme system.

\section{Analysis of cytogenetic damage}

Cytogenetic damage included chromosome aberrations, micronuclei, and sister chromatid exchange. Venous blood from all 92 subjects was drawn into heparinized test tubes, and lymphocyte cultures (two cultures/cytogenetic end point) were established within $6 \mathrm{~h}$ of the sampling. The cell culturing techniques and staining procedures for chromosome aberrations and sister chromatid exchange were as described by Lambert et al (27) with the following two modifications: (i) the concentration of 5-bromo-2'-deoxyuridine in the sister chromatid exchange cultures was $30 \mu \mathrm{M}$, and the aberration cultures were grown for $48 \mathrm{~h}$. The micronuclei culturing techniques and staining procedures were as described by Högstedt for lymphocytes with preserved cytoplasm (28), but the cultures were grown for $78 \mathrm{~h}$. All the cytogenetic scoring was made on coded slides. Aberration scoring, based on $\geq 150$ metaphases, adhered to the criteria outlined by the Standing Committee on Human Cytogenetic Nomenclature (29) and by Brögger et al (30). The scoring of micronuclei was according to Högstedt (28) and performed on 2000 interphase cells. The number of sister chromatid exchanges, including centromeric exchanges, was recorded for 40 second-division metaphase cells with 46 chromosomes. Micronucleus and sister chromatid exchange ratings were made for all the subjects who yielded a sufficient number of scorable cells ( 81 and 91 subjects, respectively). Scoring of chromosome aberrations was confined to 11 nonsmoking subjects working in the most exposed jobs in coke production and their 11 matched referents. The results of the cytogenetic scoring is given for the chromosome aberrations as the number of cells with aberrations, excluding gaps, expressed as the percentage, for the micronuclei as the number of cells with micronuclei per thousand, and for the sister chromatid exchange as the mean number of sister chromatid exchanges per cell.

\section{Statistical methods}

Student's t-test was used in the group comparisons of the results of the analyses of thioether excretion and mutagenicity. Individual results of the mutagenicity tests were determined by linear regression analysis (26). Nonparametric statistical methods (31) were applied in the basic statistical analyses of the cytogenetic data and when the correlations between different biological markers and ambient air concentrations of PAH were evaluated.

The influence on the micronucleus and sister chromatid exchange rates by the factors age/employment time and smoke and snuff habits was studied by multiple linear regression with indicator variables (32). As the frequency of micronuclei was low, Whor- 
ton's "average square root transformation" $1 / 2(\sqrt{y}$ $+\sqrt{\mathrm{y}+1}$ ) was applied to the individual scoring results (using $\mathrm{y}=$ number of micronuclei $/ 1000$ cells) to stabilize the variance (33). For the results of the sister chromatid exchanges, the regression analysis require-

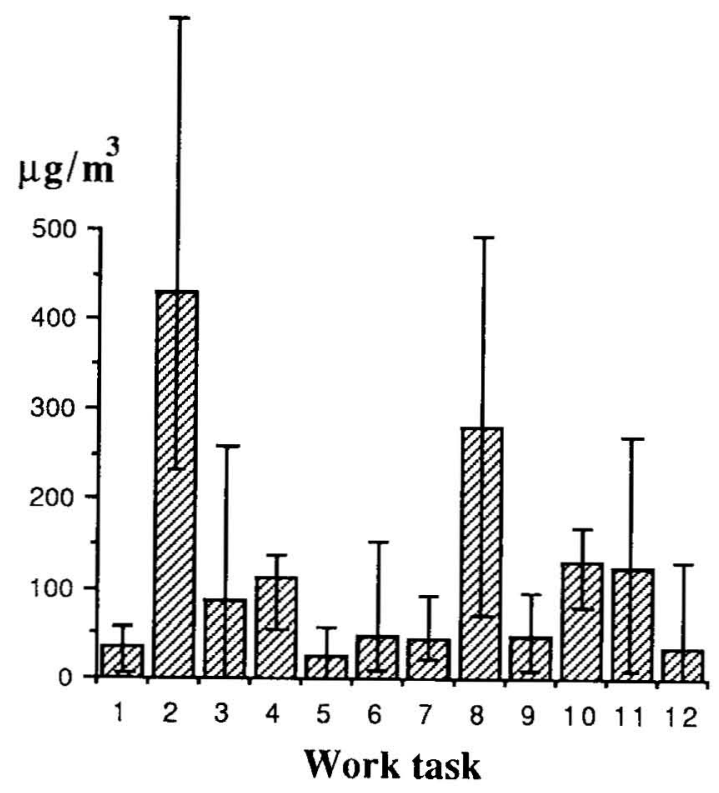

Figure 1. Total PAH exposure (8-h time-weighted average) associated with the different coke oven jobs (work tasks). The total PAH exposure is the sum of the concentrations of the following 14 polycyclic aromatic hydrocarbons: anthracene, benz[a]anthracene, dibenz[a,h]anthracene, benzo[a]fluorene, benzo[a]pyrene, benzo[b]fluoranthene, benzo[k]fluoranthene, benzo[g,h,i]perylene, chrysene, fluoranthene, fluorene, naphthalene, phenanthrene, pyrene. (hatched bars = mean concentrations; horizontal lines = highest and lowest concentrations; jobs/titles: 1 = coal conveyer operator, 2 = charging car operator, $3=$ pusher operator, $4=$ coke guide operator, $5=$ quench locomotive operator, $6=$ wharfman, $7=$ heaterman, $8=$ jamb \& door cleaner, $9=$ oven repair man, $10=$ heater supervisor, $11=$ valveman, 12 = coke sorting operator) ment of residuals that are approximately distributed normally (34) was met without transformation. For the total study group, the regression model was $y=$ intercept $+b_{1}$ (age) $+b_{2}$ (smoking) $+b_{3}$ (snuff use) $+b_{4}$ (exposure). The explanatory variables smoking, snuff use, and exposure were dichotomized (smoker $=1$, nonsmoker $=0$; snuff user $=1$, nonuser of $\operatorname{snuff}=0$; exposed $=1$, referent $=0$ ), while age was age in years at the sampling time. Smokers were also analyzed according to the model $y=$ intercept $+b_{1}$ (age in years) + $b_{2}$ (number of cigarettes smoked/d) $+b_{3}$ (exposure), exposure being dichotomized as for the total group. The hypothesis that a particular regression coefficient equals zero was tested by the t-test with conventional two-sided significance levels (32).

The SAS (statistical analysis system) package was used for the analyses (35). An alpha value of $5 \%$ was chosen as the statistical significance level, and the Pvalues refer to the two-sided hypothesis test.

\section{Results}

Ambient air concentrations of polycyclic aromatic hydrocarbons, benzene, carbon monoxide and sulfur dioxide

Twenty-four exposed subjects and four referents, all nonsmokers, carried personal air sampling equipment for the PAH and benzene analyses during a full workshift $(8 \mathrm{~h})$. All 12 coke-oven jobs and four different steel roll mill jobs were represented.

Polycyclic aromatic hydrocarbons. A total of 93 samples was analyzed for each of the 14 single PAH. The total PAH exposure (the sum of the concentrations of the $14 \mathrm{PAH}$, expressed as the 8-h time-weighted average) ranged from 6 to $570 \mu \mathrm{g} / \mathrm{m}^{3}$ among the cokeoven workers. The average total PAH exposure, associated with the 12 coke-oven jobs, is shown in fig-

Table 1. Urinary thioether excretion ( $\mathrm{mmol} / \mathrm{mol}$ creatinine) of the exposed and reference groups.

\begin{tabular}{|c|c|c|c|c|c|c|c|}
\hline & \multirow{3}{*}{$\begin{array}{c}\text { Number } \\
\text { of subjects }\end{array}$} & \multicolumn{6}{|c|}{ Sampling occasion } \\
\hline & & \multicolumn{2}{|c|}{ Before shift } & \multicolumn{2}{|c|}{ After shift } & \multicolumn{2}{|c|}{ Off work } \\
\hline & & Mean & SD & Mean & $S D$ & Mean & SD \\
\hline \multicolumn{8}{|l|}{ No-tobacco users } \\
\hline $\begin{array}{l}\text { Exposed group } \\
\text { Reference group }\end{array}$ & $\begin{array}{l}16 \\
19\end{array}$ & $\begin{array}{l}4.9 \\
4.6\end{array}$ & $\begin{array}{l}1.7 \\
0.8\end{array}$ & $\begin{array}{l}4.7 \\
4.5\end{array}$ & $\begin{array}{l}1.5 \\
0.7\end{array}$ & $\begin{array}{l}5.0^{\mathrm{a}} \\
-\end{array}$ & $\stackrel{1.3}{-}$ \\
\hline \multicolumn{8}{|l|}{ Snuff users } \\
\hline $\begin{array}{l}\text { Exposed group } \\
\text { Reference group }\end{array}$ & $\begin{array}{l}8 \\
9\end{array}$ & $\begin{array}{l}4.5 \\
4.7\end{array}$ & $\begin{array}{l}1.1 \\
0.8\end{array}$ & $\begin{array}{l}4.5 \\
4.7\end{array}$ & $\begin{array}{l}0.7 \\
0.7\end{array}$ & $-^{5.3^{b}}$ & 1.7 \\
\hline \multicolumn{8}{|l|}{ Smokers*** } \\
\hline $\begin{array}{l}\text { Exposed group } \\
\text { Reference group }\end{array}$ & $\begin{array}{l}4 \\
6\end{array}$ & $\begin{array}{l}6.3 \\
6.9\end{array}$ & $\begin{array}{l}1.4 \\
1.0\end{array}$ & $\begin{array}{l}6.0 \\
6.9\end{array}$ & $\begin{array}{l}0.6 \\
2.1\end{array}$ & $\frac{6.5}{-}$ & 1.2 \\
\hline
\end{tabular}

a $\mathrm{N}=12$ (shift workers only); their after shift mean excretion was $4.8 \mathrm{mmol} / \mathrm{mol}$ creatinine.

b $\mathrm{N}=7$ (shift workers only); their after shift mean excretion was $4.6 \mathrm{mmol} / \mathrm{mol}$ creatinine.

$\because * t=4.8, d f=60, P<0.001$ for smokers versus nonsmokers (after shift rates, exposed and referents combined). 
ure 1 (averages based on 3-13 samples/job). Naphthalene was the dominating single PAH $(60-95 \%$ of the total PAH exposure) for all the coke-oven jobs. The phenanthrene concentration varied between 1 and $17 \%$ for the different jobs, and the remaining $\mathrm{PAH}$ usually occurred in small fractions, $3 \%$ or less each. Benzo[a]pyrene constituted approximately $0.5-2.5 \%$ of the total PAH concentration. When the different jobs were compared, the benzo[a]pyrene exposure closely paralleled the total PAH concentration. The benzo[a]pyrene exposure, expressed as the 8-h timeweighted average, exceeded the Swedish occupational exposure limit $\left(5 \mu \mathrm{g} / \mathrm{m}^{3}\right)$ for the job "jamb \& door cleaner"' and was $70 \%$ of the limit for "charging car operators." PAH exposure in the steel roll mill was very low, the highest total $\mathrm{PAH}$ concentration being less than $2 \mu \mathrm{g} / \mathrm{m}^{3}$.

Benzene. The highest benzene concentration, 0.6 $\mathrm{mg} / \mathrm{m}^{3}$, was observed for the job of "charging car operator." (The current Swedish 8-h occupational exposure limit is $3 \mathrm{mg} / \mathrm{m}^{3}$.) Benzene did not occur at all in the steel roll mill.

Carbon monoxide and sulfur dioxide. The carbon monoxide concentrations in the coke works ranged from below the detection limit $(5 \mathrm{ppm})$ to $50 \mathrm{ppm}$ (100 ppm being the Swedish occupational exposure limit) at nine sites monitored by 16 samples. The sulfur dioxide concentrations were below the detection limit $(0.5 \mathrm{ppm})$, except for one coke works sample (2 ppm).

In the steel roll mill, the carbon monoxide and sulfur dioxide concentrations were monitored by six samples each, at two sites. The carbon monoxide concentration was below the detection limit in all the samples, and the sulfur dioxide concentration exceeded the detection limit in only one sample ( $3 \mathrm{ppm})$.

\section{Urinary thioether excretion}

The results of the thioether determinations are summarized in table 1. Among the coke-oven workers, neither acute nor accumulated exposure seemed to increase the rates of thioether excretion, as judged from comparisons of preshift samples with postshift samples and off-work samples. Furthermore, there were no differences in the excretion rates between the cokeoven workers and the steel roll mill workers. The mean thioether concentration of the five nonsmoking subjects working as charging car operators and jamb \& door cleaners (the jobs with the highest PAH exposure) was even lower than that of the other nonsmoking coke-oven workers and the nonsmoking referents. The use of snuff did not influence the thioether excretion. Tobacco smoking, on the other hand, significantly increased the excretion rates, regardless of exposure sta- tus $(t=4.8$, degrees of freedom $=60, P<0.001$; postshift excretion rates, exposed and referents combined).

\section{Urine mutagenicity}

The urine concentrates from two samples were toxic to the bacteria and were excluded. The mutagenicity results are thus based on data from 29 subjects (ie, 11 exposed, only nonsmokers, and 18 referents, nonsmokers and smokers). The use of snuff had no effect on the urine mutagenicity level, and data from the snuff users and the subjects using no tobacco were therefore combined.

Neither acute nor accumulated exposure to PAH seemed to influence the mean levels of urine mutagenicity, while tobacco smoking increased the mutagenicity significantly (table 2 ).

\section{Cytogenetic damage}

According to the criteria for the cytogenetic analyses, 80 subjects were scored for both micronuclei and sister chromatid exchanges, one subject was scored for micronuclei only, and another 11 subjects were scored only for sister chromatid exchanges. The samples from all 11 referents selected for the chromosome aberration scoring could be analyzed, while the cell cultures from only seven of the selected exposed subjects yielded the minimum 150 metaphases for chromosome aberration analysis.

The levels of cytogenetic damage in different groups are shown in table 3 . The exposed subjects had slightly higher rates of chromosome aberrations than the referents, but the difference was not statistically significant (Wilcoxon's rank sum test $z=0.97, N=18$, $\mathrm{P}>0.3$ ). The number of "gaps" did not differ between the groups.

The results of the multiple regression analyses are summarized in table 4. Age and employment time were strongly correlated in the study group $\left(\mathrm{rho}_{\mathrm{S}}=0.7\right.$, $\mathrm{P}<0.001$ ). Using employment time, instead of age, as the explanatory variable increased the regression model fit to the micronucleus results, while the reverse was true for the sister chromatid exchange results. Only a

Table 2. Urinary mutagenicity of the exposed and reference groups.

\begin{tabular}{|c|c|c|c|c|c|}
\hline \multirow{3}{*}{ Group } & \multirow{3}{*}{$\begin{array}{l}\text { Number } \\
\text { of } \\
\text { subjects }\end{array}$} & \multicolumn{4}{|c|}{ Mutants } \\
\hline & & \multicolumn{2}{|c|}{$\begin{array}{c}\text { Number } / \mathrm{ml} \\
\text { urine }\end{array}$} & \multicolumn{2}{|c|}{$\begin{array}{c}\text { Numberlumol } \\
\text { creatinine }\end{array}$} \\
\hline & & Mean & SD & Mean & SD \\
\hline \multicolumn{6}{|l|}{ Exposed } \\
\hline $\begin{array}{l}\text { Nonsmokers, }{ }^{a} \text { after shift } \\
\text { Nonsmokers, }{ }^{a} \text { after } 7 \mathrm{~d}\end{array}$ & 11 & 1.0 & 2.7 & 0.06 & 0.16 \\
\hline off work & 11 & 2.6 & 2.3 & 0.26 & 0.25 \\
\hline \multicolumn{6}{|l|}{ Referents } \\
\hline $\begin{array}{l}\text { Nonsmokers, }{ }^{a} \text { after shift } \\
\text { Smokers, after shift }\end{array}$ & $\begin{array}{c}13^{b} \\
5\end{array}$ & $\begin{array}{r}2.3 \\
42.8\end{array}$ & $\begin{array}{l}3.5 \\
31.2^{\star * *}\end{array}$ & $\begin{array}{l}0.21 \\
3.14\end{array}$ & $\begin{array}{l}0.31 \\
2.60^{\star *}\end{array}$ \\
\hline
\end{tabular}

a Snuff users and subjects not using tobacco at all combined.

b Two samples were toxic and thus deleted.

$* * \mathrm{P}<0.001$, t-test (smokers versus nonsmokers) 
Table 3. Cytogenetic damage in the different groups: median number of chromosome aberrations and micronuclei and mean and standard deviation of sister chromatid exchanges. ( $N=$ number of subjects)

\begin{tabular}{|c|c|c|c|c|c|c|c|}
\hline & \multicolumn{7}{|c|}{ End point } \\
\hline & \multicolumn{2}{|c|}{$\begin{array}{l}\text { Chromosome } \\
\text { aberrations }^{\mathrm{a}}\end{array}$} & \multicolumn{2}{|c|}{ Micronuclei ${ }^{b}$} & \multicolumn{3}{|c|}{ Sister chromatid exchange ${ }^{b}$} \\
\hline & $N$ & Median & $N$ & Median & $N$ & Mean & $\mathrm{SD}$ \\
\hline \multicolumn{8}{|l|}{ Exposed group } \\
\hline $\begin{array}{l}\text { No-tobacco users } \\
\text { Smokers } \\
\text { Snuff users }\end{array}$ & $\frac{3}{4}$ & $\begin{array}{l}1.6 \\
\dot{2} \\
2.0\end{array}$ & $\begin{array}{l}20 \\
10 \\
13\end{array}$ & $\begin{array}{l}5.0 \\
4.2 \\
4.0\end{array}$ & $\begin{array}{l}21 \\
10 \\
13\end{array}$ & $\begin{array}{r}8.2 \\
10.2 \\
8.7\end{array}$ & $\begin{array}{l}1.1 \\
1.4 \\
1.1\end{array}$ \\
\hline \multicolumn{8}{|l|}{ Reference group } \\
\hline $\begin{array}{l}\text { No-tobacco users } \\
\text { Smokers } \\
\text { Snuff users }\end{array}$ & $\frac{5}{6}$ & $\begin{array}{c}1.0 \\
1.3\end{array}$ & $\begin{array}{l}17 \\
10 \\
11\end{array}$ & $\begin{array}{l}4.5 \\
5.0 \\
4.5\end{array}$ & $\begin{array}{l}22 \\
13 \\
12\end{array}$ & $\begin{array}{l}8.2 \\
9.8 \\
8.7\end{array}$ & $\begin{array}{l}1.1 \\
1.3 \\
1.4\end{array}$ \\
\hline
\end{tabular}

a Wilcoxon's rank sum test, $z=0.97, N=18, P>0.3$ (exposed versus reference group).

b Results of the statistical analysis are given in table 4.

Table 4. Coefficients $(b)$ and standard error of coefficients $\left(\mathrm{SE}_{\mathrm{b}}\right)$ from multiple regression analyses of micronuclei and sister chromatid exchanges. The coefficients from the micronucleus analysis refer to the transformed values of the dependent variable (average square root of micronuclei) as described in the text. The dichotomization of the smoke, snuff, and exposure variables has been described in the text. ( $N=$ number of subjects, $r^{2}$ adj $=$ explained proportion of the variation, adjusted for the number of parameters in the model)

\begin{tabular}{|c|c|c|c|c|c|}
\hline End point & $N$ & $r^{2}{ }_{\text {adj }}$ & $\mathrm{b}$ & $\mathrm{SE}_{\mathrm{b}}$ & $P\left(H_{0}: \beta=0\right)$ \\
\hline Micronuclei & 81 & 0.05 & . & . & . \\
\hline $\begin{array}{l}\text { Employment time (years) } \\
\text { Smoking }(1 / 0) \\
\text { Snuff habits }(1 / 0) \\
\text { Exposure }(1 / 0)\end{array}$ & $\dot{.}$ & $\dot{.}$ & $\begin{array}{r}0.02 \\
0.01 \\
-0.07 \\
0.04\end{array}$ & $\begin{array}{l}0.01 \\
0.14 \\
0.13 \\
0.11\end{array}$ & $\begin{array}{l}0.01 \\
0.9 \\
0.6 \\
0.7\end{array}$ \\
\hline \multicolumn{6}{|l|}{ Sister chromatid exchanges } \\
\hline All subjects & 91 & 0.25 & . & . & . \\
\hline $\begin{array}{l}\text { Age (years) } \\
\text { Smoking }(1 / 0) \\
\text { Snuff habits }(1 / 0) \\
\text { Exposure }(1 / 0)\end{array}$ & $\begin{array}{l}\dot{.} \\
\dot{.}\end{array}$ & $\dot{.}$ & $\begin{array}{l}0.02 \\
1.81 \\
0.59 \\
0.02\end{array}$ & $\begin{array}{l}0.01 \\
0.32 \\
0.32 \\
0.26\end{array}$ & $\begin{array}{c}0.05 \\
<0.001 \\
0.07 \\
0.9\end{array}$ \\
\hline Only smokers & 23 & 0.04 & . & $\cdot$ & . \\
\hline $\begin{array}{l}\text { Age (years) } \\
\text { Smoking (number of cigarettes/d) } \\
\text { Exposure }(1 / 0)\end{array}$ & $\dot{.}$ & $\dot{.}$ & $\begin{array}{r}0.05 \\
-0.01 \\
0.30\end{array}$ & $\begin{array}{l}0.02 \\
0.06 \\
0.58\end{array}$ & $\begin{array}{l}0.08 \\
0.8 \\
0.6\end{array}$ \\
\hline
\end{tabular}

small fraction $(5 \%)$ of the total variability of the micronucleus frequency was explained by the factors controlled for in the present study, namely, age/employment time, smoking, snuff habits, and exposure. Neither coke-oven work nor smoking or snuff use influenced the frequency of micronuclei, while longer employment time was associated with a higher frequency of micronuclei. (Substituting employment time for age in the regression model showed the age effect to be almost statistically significant, $b=0.01 \pm 0.005$, $\mathbf{P}=0.06$.) Age, smoking, snuff habits, and exposure status accounted together for $25 \%$ of the total variability in the number of sister chromatid exchanges (table 4). Smoking, as well as increasing age, added to the means of the sister chromatid exchanges. Use of snuff also tended to increase the sister chromatid exchange levels. Among the smokers, the number of cigarettes smoked per day did not influence the means of the sister chromatid exchanges.

\section{Correlation between the biological markers}

Several subjects were studied for more than one biological parameter, and the association between individual measurements was evaluated by the Spearman's rho $\left(\right.$ rho $_{\mathrm{S}}$ ) correlation coefficient.

The individual frequencies of the micronuclei and sister chromatid exchanges were not correlated among the whole study group $\left(\mathrm{rho}_{\mathrm{S}}=0.04, \mathrm{P}=0.97, \mathrm{~N}=80\right.$ ) or among the smokers or nonsmokers. There was a statistically significant positive association between the frequency of sister chromatid exchanges and the thioether excretion rates $\left(\mathrm{rho}_{\mathrm{S}}=0.46, \mathrm{~N}=60, \mathrm{P}<0.001\right)$ and a weaker correlation between the frequency of sister chromatid exchanges and urine mutagenicity (rho $_{\mathrm{S}}=0.31, \mathrm{~N}=29, \mathrm{P}=0.10$ ); the $\mathrm{rho}_{\mathrm{S}}$ point estimates for the remaining combinations of markers ranged from 0.15 to -0.05 . The analysis of the results of the nonsmokers, separated with respect to exposure status, revealed a statistically significant correlation 
between the frequency of sister chromatid exchanges and the thioether excretion in the exposed group (rho $\mathrm{S}=0.47, \mathrm{~N}=24, \mathrm{P}=\mathbf{0 . 0 2}$ ) but not in the reference group $\left(\mathrm{rho}_{\mathrm{S}}=0.01, \mathrm{~N}=27\right)$.

\section{Correlation between exposure to polycyclic aromatic hydrocarbons and the biological markers}

Data on the individual exposure to the different PAH were available for 24 subjects in the exposed group, all nonsmokers. In summary, the frequency of sister chromatid exchanges and urine mutagenicity were both weakly, but positively correlated with individual exposure to 13 of the $14 \mathrm{PAH}$ analyzed (point estimates of $\mathrm{rho}_{\mathrm{S}}$ ranged from 0.01 to 0.38 , except for fluoranthene). A significant association was found between fluoranthene exposure and the urine mutagenicity rate (rho ${ }_{S}=0.63, N=11, P=0.04$ ). The frequency of micronuclei and the thioether excretion rate were both weakly negatively associated with individual exposure to the different $\mathrm{PAH}$, the rho $\mathrm{s}_{\mathrm{S}}$ ranging from -0.06 to $-\mathbf{0 . 3 2}$. The point estimate of the correlation ( $\mathrm{rho}_{\mathrm{S}}$ ) between benzo[a]pyrene and the different biological markers was -0.25 for thioether excretion, 0.18 for urine mutagenicity, -0.26 for micronuclei frequency, and 0.05 for the frequency of sister chromatid exchanges.

\section{Discussion}

Polycyclic aromatic hydrocarbons in the ambient air Significant amounts of PAH were found only at the coke works. The analyses of the breathing-zone air indicated that the proportions of the different polycyclic aromatic hydrocarbons were similar for all the studied jobs, and these proportions were in accordance with the distributions previously reported in smoke from coke ovens (23). The PAH exposure levels for the different coke-oven jobs were of the same order of magnitude as reported in recent studies of coke works (36-38), or somewhat lower. Jamb \& door cleaners were exposed to concentrations of benzo[a]pyrene exceeding the current Swedish occupational exposure limit ( $5 \mu \mathrm{g} / \mathrm{m}^{3}, 8$-h time-weighted average), and the exposure level of the charging car operators was $70 \%$ of the limit.

\section{Biological markers}

The lack of a biological indication of genotoxic exposure related to coke-oven work was unexpected. Previous studies have reported elevated levels of urine mutagenicity $(6,7)$ and sister chromatid exchanges $(3,5)$ among coke-oven workers. Since cigarette smoking was found to increase thioether excretion in the urine, urine mutagenicity, and the mean number of sister chromatid exchanges - as expected - we do not think that the absence of effect from coke-oven work in our study was due to mistakes in handling and analyzing the biological samples.

Half of the coke-oven workers used disposable halfface dust respirators more or less extensively. Such paper masks may protect against particulate PAH, but the protective capacity has not been documented under the present work conditions. Exposure to gaseous PAH cannot be reduced by the wearing of such masks, however. There were no differences in the levels of cytogenetic damage, urine mutagenicity, or thioether excretion that could be attributed to the use of the paper masks, neither among subjects wearing personal air sampling equipment nor among all the subjects from the coke works. The proportions of particulate and gaseous PAH in air samples from the battery top of the coke oven have been given earlier (23).

Regarding the thioether excretion, it is possible that the metabolism of the electrophilic compounds through glutathione conjugation was low, and the analysis was not sensitive enough to detect such a low rate. Alternatively, the glutathione conjugates may have been excreted via the bile (39). The third explanation for the negative results of the thioether assay may be that electrophilic compounds causing lung cancer are not absorbed by the blood stream.

The excretion of unchanged PAH or metabolites that are active in the Salmonella mutagenicity test may not relate linearly to the exposure levels. Uptake and urinary excretion is, for example, dependent on the bioavailability of the PAH adsorbed on airborne particulate matter, as shown, for instance, in a group of PAH-exposed aluminum smelter workers (40). Møller \& Dybing (8) studied urine mutagenicity among Norwegian coke plant workers and found no effect that could be attributed to the occupational exposure, while smoking subjects had significantly higher urine mutagenicity rates than nonsmokers. They discussed these results in relation to published data on urine benzo[a]pyrene concentrations in smokers and in nonsmoking coke-oven workers - indicating substantially higher benzo[a]pyrene contents in urine from cokeoven workers than in urine from smokers - and concluded that tobacco smoke components other than pure PAH may be responsible for the strong mutagenic effect of smokers' urine (8). This finding suggests that benzo[a]pyrene, although mutagenic, is not a good indicator of genotoxic exposure to tobacco smoke.

Since only 18 subjects were scored for chromosome aberrations in the present study, the "negative" results only exclude strong effects from the coke-oven work. [The point estimates of the chromosome aberration rates were in fact higher in the exposed group (table 3)]. Previously published results do not suggest that the rate of chromosome aberrations increases dramatically due to exposure to coal-tar pitch volatiles, even at exposure levels above those in the present study $(3,4)$. Chromosome aberrations may thus be a somewhat insensitive indicator of biological effects from this kind of PAH exposure. 
Elevated rates of micronuclei may reflect increased numbers of chromosome and chromatid breaks and/or spindle disturbances. With reference to the low rates of chromosome aberrations in both the exposed and reference subjects, it is not unreasonable that the micronuclei rates were similar in the two groups. The positive correlation found between age and the rate of micronuclei agrees with results from other studies (17) and makes it less likely that the absence of exposure effects on the micronuclei rates was due to methodological errors in the micronucleus analysis.

Two previous American studies on the frequency of sister chromatid exchanges of coke-oven workers found significantly higher means for the exposed groups $(3,5)$. The average exposure level in the study by Miner et al, $0.06 \mathrm{mg} / \mathrm{m}^{3}$ of benzene-soluble matter (5), was approximately the same as the highest exposure (of the jamb \& door cleaners) in the present study. The exposure levels in the study by Bender et al ranged from 18 to $19533 \mathrm{mg}$ of coal-tar pitch volatiles/mg and year (3) and were thus substantially higher, at least for some jobs, than the exposure levels of our study. The difference in the means of the sister chromatid exchanges between the exposed and reference groups was about $13 \%$ for both studies. Simple power calculations, based on the observed mean and standard deviation of the sister chromatid exchanges for our reference group, indicate that, under the present conditions, it should be possible to detect a $9 \%$ increase in the means of sister chromatid exchanges among nonsmoking exposed subjects, when they are compared with nonsmoking referents (one-sided nonparametric test, $\alpha=0.05$, statistical power $80 \%$ ). The corresponding figure for smoking subjects should be $13.5 \%$. The smoking referents had higher frequencies of sister chromatid exchanges than the nonsmoking exposed subjects (Wilcoxon's $\mathrm{z}=3.1, \mathrm{P}=0.002$ ); this finding may mean that the effect of the coke-oven exposure on sister chromatid exchange does not exceed the effect of smoking $\geq 10$ cigarettes/d.

Since cigarette smoking influences thioether excretion, urine mutagenicity, and the frequency of sister chromatid exchanges, one could expect a stronger correlation between these end points among smokers than among nonsmokers. Only a few urine samples from smokers were analyzed in the present study, but the point estimates of these correlations were approximately $0.5\left(\mathrm{rho}_{\mathrm{S}}\right)$ among the smokers. Among the nonsmokers these correlations were consistently weaker, and urine mutagenicity was even negatively correlated with each of the end points of sister chromatid exchanges, micronuclei, and thioether excretion.

The frequency of sister chromatid exchanges and thioether excretion were positively correlated among the nonsmokers in the exposed group, but there was no such association among the nonsmoking referents. It is not clear whether this finding reflects an effect of coke-oven smoke exposure, however. For instance, the correlation between exposure to single PAH was positively associated with the frequency of sister chromatid exchanges but negatively associated with the thioether excretion rates.

\section{Concluding remarks}

The objective of this investigation was to study the potential benefits and limitations of some methods for biological monitoring when used simultaneously. Compared with the normal monitoring situation, a more careful study design probably resulted, including choice of referents and control of potential confounders (age, sex, smoking, snuff consumption, chronic and acute diseases and medication, nonwork genotoxic exposure, diet standardization, sampling schemes, etc). The risk of obtaining false positive results should thus have been small in the present study. The number of subjects studied was also large enough to permit detection of even moderate increases in the rates of the biological end points, and therefore the probability of obtaining false negative results was low.

The absence of biological indications of the exposure associated with coke-oven work was unexpected. If one rules out methodological errors, there are two main explanations for these findings: (i) there is no increased risk of genotoxic exposure associated with this work or (ii) the monitoring methods were not adequate to reveal such an exposure. Given the evidence of increased cancer risks in connection with coke production (2) without a threshold of no effect and given the levels of PAH exposure found in this study, we conclude that the methods of biological monitoring studied - urinary thioether excretion, urine mutagenicity, and cytogenetic damage in peripheral lymphocytes - are not suitable for monitoring mutagenic/carcinogenic exposure in a work environment similar to the one at this Swedish coke works. The basis for this assumption could be that the methods are not well suited to reflect genotoxic effects in the target tissue. Monitoring methods assessing the induction of point mutations in different tissues might be more useful as effect indicators; the development of such methods is in progress, but they do not seem to be ready for application in routine studies. Urinary excretion of 1-hydroxypyrene has been used in biological monitoring for PAH exposure. Jongeneelen and his co-workers found increased urinary levels of 1-hydroxypyrene among workers exposed to creosote oil (41-42), among coaltar distillery workers (43), and among road paving workers using tar-blended binders (44). Swedish cokeoven workers and aluminum smelter workers are currently being monitored for 1-hydroxypyrene excretion (45), and this pyrene metabolite is expected to become a suitable biological indicator of internal PAH exposure.

Recent observations propose carcinogenic agents acting as promoters in cigarette smoke to be critical for the induction of smoke-related lung cancer (10). Epidemiologic studies of coke-oven workers have fre- 
quently reported excess risks of lung cancer. (See references in 2 and 46.) This risk might, analogously, be explained by the occurrence of such promoters in the coke-oven smoke. However, methods detecting carcinogens or substances that enhance cancer development have not yet been established for routine monitoring.

\section{Acknowledgments}

The study was supported by grants from the Swedish Work Environment Fund to the National Board of Occupational Safety and Health.

We gratefully acknowledge the cooperation of Ms M Einar, Ms B Herberthson, Dr U Tallgren, Mr A Aouja, and $\mathrm{Mr}$ A Forsgren in obtaining the samples and all the workers who volunteered to participate. Our sincere thanks are also due to Ms M Ekdahl, Ms R Eriksson, Ms B Gillstedt-Hedman, Mr G Hägg, Mr M Olsson, and Ms A Pehrsson, who skillfully carried out the different analyses. Finally, we wish to thank Professor L Rosenstock for her valuable comments on the manuscript.

\section{References}

1. Berlin A, Draper M, Hemminki K, Vainio H. Summary. In: Berlin A, Draper M, Hemminki K, Vainio H, ed. Monitoring human exposure to carcinogenic and mutagenic agents. Lyon: International Agency for Research on Cancer, 1984:23-8. (IARC scientific publications; no 59.)

2. International Agency for Research on Cancer. Overall evaluation of carcinogenicity: an updating of IARC monographs volumes 1 to 42. Lyon: International Agency for Research on Cancer, 1987. (IARC monographs on the evaluation of carcinogenic risks to humans; suppl 7.)

3. Bender MA, Leonard RC, White O Jr, Costantino JP, Redmond CK. Chromosomal aberrations and sister chromatid exchanges in lymphocytes from coke oven workers. Mutat Res 1988;206:11-6.

4. Heussner JC, Ward Jr JB, Legator MS. Genetic monitoring of aluminium workers exposed to coal tar pitch volatiles. Mutat Res 1985;155:143-55.

5. Miner JK, Rom WN, Livingston GK, Lyon JL. Lymphocyte sister chromatid exchange (SCE) frequencies in coke oven workers. J Occup Med 1983;25:30-3.

6. De Méo M, Duménil G, Botta AH, Laget M, Zabaloueff $\mathrm{V}$, Mathias A. Urine mutagenicity of steel workers exposed to coke oven emissions. Carcinogenesis 1987; 8:363-7.

7. Kriebel D, Commoner B, Bollinger D, Bronsdon A, Gold J, Henry J. Detection of occupational exposure to genotoxic agents with a urinary mutagen assay. Mutat Res 1983;108:67-79.

8. Møller M, Dybing E. Mutagenicity studies with urine concentrates from coke plant workers. Scand J Work Environ Health 1980;6:216-20.

9. Triebig G, Schaller K-H, Wagner M, Weltle D, Moser $\mathrm{S}$, Valentin $\mathrm{H}$. A pilot study of the diagnostic validity of urinary thioether excretion in occupational medicine. Sci Total Environ 1988;71:231-4.

10. International Agency for Research on Cancer. Tobacco smoking. Lyon: International Agency for Research on Cancer, 1986. (IARC monographs on the evaluation of carcinogenic risk of chemicals to humans; vol 38.)

11. Evans HJ. Sister chromatid exchanges and disease states in man. In: Wolff $\mathrm{S}$, ed. Sister chromatid exchange. New York, NY: John Wiley \& Sons, 1982:183- 228.

12. Lambert $\mathbf{B}$, Olin $\mathbf{R}$. Individual variability in the frequency of sister chromatid exchange in human lymphocytes. In: de Serres FJ, Pero RW, ed. Individual susceptibility to genotoxic agents in the human population. New York, NY: Plenum Publishing Co, 1984:211-33.

13. Minnich V, Smith ME, Thompson D, Kornfeld S. Detection of mutagen activity in human urine using mutant strains of Salmonella typhimurium. Cancer 1976; 38: $1253-8$.

14. Vainio H, Savolainen H, Kilpikari I. Urinary thioether of employees of a chemical plant. Br J Ind Med 1978; $35: 232-4$.

15. Mitelman F, Wadstein J. Chromosome aberrations in chronic alcoholics. Lancet 1978;1:216.

16. Anderson D, Jenkinson PC, Dewdney RS, Francis AJ, Godbert P, Butterworth KR. Chromosome aberrations, mitogen-induced blastogenesis and proliferative rate index in peripheral lymphocytes from 106 control individuals of the UK population. Mutat Res 1988;204:407-20.

17. Nordic Study Group on the Health Risk of Chromosome Damage. A Nordic data base on somatic chromosome damage in humans. Mutat Res 1990;241:325-37.

18. Soper KA, Stolley PD, Galloway SM, Smith JG, Nichols WW, Wolman SR. Sister-chromatid exchange (SCE) report on control subjects in a study of occupationally exposed workers. Mutat Res 1984;129:77-88.

19. Tawn EJ. The frequency of chromosome aberrations in a control population. Mutat Res 1987;182:303-8.

20. Aringer L, Lidums V. Influence of diet and other factors on urinary levels of thioethers. Int Arch Occup Environ Health 1988;61:123-30.

21. Baker R, Arlauskas A, Bonin A, Angus D. Detection of mutagenic activity in human urine following fried pork or bacon meals. Cancer Lett 1983;16:81-9.

22. Knize MG, Andresen BD, Healy SK, et al. Effects of temperature, patty thickness and fat content on the production of mutagens in fried ground beef. Food Chem Toxicol 1985;123:1035-40.

23. Andersson K, Levin J-O, Nilsson C-A. Sampling and analysis of particulate and gaseous polycyclic aromatic hydrocarbons from coal tar sources in the working environment. Chemosphere 1983;12:197-207.

24. Bartels H, Böhmer M, Heierli C. Serum-Kreatinin-bestimmung ohne Enteiweissen. Clin Chim Acta 1972; 37: 193-7.

25. Maron DM, Ames BN. Revised methods for the Salmonella mutagenicity test. Mutat Res 1983;113: $173-215$.

26. Rannug A, Olsson M, Aringer L, Brunius G. An improved standardized procedure for urine mutagenicity testing. In: Bartsch $\mathrm{H}$, Hemminki K, O'Neill IK ed. Methods for detecting DNA damaging agents in humans: applications in cancer epidemiology and prevention. Lyon: International Agency for Research on Cancer 1988:396-400. (IARC scientific publications; no 89.)

27. Lambert B, Hansson K, Lindsten J, Sten M, Werelius B. Bromodeoxyuridine-induced sister chromatid exchanges in human lymphocytes. Hereditas 1976;83: $163-74$

28. Högstedt B. Micronuclei in lymphocytes with preserved cytoplasm: a method for assessment of cytogenetic damage in man. Mutat Res 1984;130:63-72.

29. International System for Human Cytogenetic Nomenclature. An international system for human cytogenetic nomenclature. Cytogenet Cell Genet 1978;21:309-404.

30. Brøgger A, Norum R, Hansteen I-L, et al. Comparison between five Nordic laboratories on scoring of human lymphocyte chromosome aberrations. Hereditas 1984; 100:209-18. 
31. Conover WJ. Practical nonparametric statistics. 2nd ed. New York, NY: John Wiley \& Sons, 1980.

32. Freund RJ, Littell RC. SAS systems for regression. Cary, NC: SAS Institute Inc, 1986.

33. Whorton EB. Some experimental design and analysis considerations for cytogenetic studies. Environ Mutagen 1985;7:9-15.

34. Kleinbaum DG, Kupper LL, Muller KE. Applied regression analysis and other multivariable methods. Boston, MA: PWS-KENT Publishing Co, 1987.

35. SAS Institute Inc, SAS user's guide: statistics, version 5 edition. Cary, NC: SAS Institute Inc, 1985.

36. Bjørseth A, Bjørseth O, Fjeldstad E. Polycyclic aromatic hydrocarbons in the work atmosphere: II. determination in a coke plant. Scand J Work Environ Health 1978; 4:224-36.

37. Jackson JO, Warner PO, Mooney TF. Profiles of benzo(a)pyrene and coal tar pitch volatiles at and in the immediate vicinity of a coke oven battery. Am Ind Hyg Assoc J 1974;35:276-81.

38. Davies GM, Hodkinson A, DiVetta P. Measurement and analysis of occupational exposures to coke oven emissions. Ann Occup Hyg 1986;13(1):51-62.

39. Elmhirst TRD, Chipman JK, Riberio O, Hirom PC, Millburn P. Metabolism and enterohepatic circulation of benzo $(a)$ pyrene-4,5-epoxide in the rat. Xenobiotica 1985;15:899-906.

40. Becher G, Bjørseth A. Determination of exposure to polycyclic aromatic hydrocarbons by analysis of human urine. Cancer Lett 1983;17:301-11.

41. Jongeneelen FJ, Anzion RBM, Leijdekkers C-M, Bos
RP, Henderson PT. 1-hydroxypyrene in human urine after exposure to coal tar and a coal tar derived product. Int Arch Environ Health 1985;57:47-55.

42. Jongeneelen FJ, Anzion RBM, Scheepers PTJ, et al. 1-hydroxypyrene in urine as a biological indicator of exposure to polycyclic aromatic hydrocarbons in several work environments. Ann Occup Hyg 1988;32:35- 43.

43. Jongeneelen FJ, Bos RP, Anzion RBM, Theuws JLG, Henderson PT. Biological monitoring of polycyclic aromatic hydrocarbons: metabolites in urine. Scand J Work Environ Health 1986;12:137-43.

44. Jongeneelen FJ, Scheepers PTJ, Groenendijk A, et al. Airborne concentrations, skin contamination and urine metabolite excretion of PAH among paving workers exposed to coal tar derived road tars. Am Ind Hyg Assoc J 1988;49:600-7.

45. Levin JO, Sikström E. Urine levels of 1-hydroxypyrene in coke oven workers. In: American Industrial Hygiene Association. American industrial hygiene conference abstracts. St Louis, MO: American Industrial Hygiene Association, 1989:56. (Abstract no 88).

46. International Agency for Research on Cancer. Polynuclear aromatic compounds, part 3: industrial exposures in aluminium production, coal gasification, coke production, and iron and steel founding. Lyon: International Agency for Research on Cancer, 1984;101-31. (IARC Monographs on the evaluation of carcinogenic risk of chemicals to humans; vol 34.)

Received for publication: 30 July 1990 